\title{
Possibilities, purpose and pitfalls: Insights from introducing mindfulness to leaders
}

\author{
Amanda Sinclair \\ Professorial Fellow \\ Melbourne Business School \\ University of Melbourne
}

\begin{abstract}
While mindfulness has been part of Buddhism and other religious and philosophical traditions for millennia, the last decades have seen adoption of mindfulness in clinical settings and more recently, in organisations and leadership. This article reports experiences introducing practices and concepts of mindfulness to managers and leaders across a wide range of sectors and organisational settings over the last ten years. I identify six particular insights that have emerged as important over that time: from how to define and explain mindfulness to leaders, through to ethical issues of the purposes to which mindfulness is put. Through discussion of these insights, I argue that mindful leadership is not a template and its introduction in organisations is not just about reducing stress and helping employees put their shoulder to the wheel of greater productivity. Rather, being mindful in leadership can be understood as a potentially radical, even subversive, act. It offers enlivening and humanising prospects for leaders and leadership, with its encouragement to see reality and challenge orthodoxies, to put a primary value on the wellbeing of others and how we live and lead now.
\end{abstract}

Key words: mindfulness, mindful leadership, management, purpose, leaders, meditation, organisational mindfulness, workplace stress

\section{INTRODUCTION}

Mindfulness is a mode of consciousness marked by a commitment to purposeful present-moment awareness (Hanh 1991; Kabat-Zinn 1994). Practices of mindfulness have been utilised for thousands of years as part of Buddhism, but the last two or three decades have also seen widespread adoption and research of mindfulness in clinical settings. More recently, ideas and practices of mindfulness have been introduced into organisations and workplaces. These include the well-publicised activities of American-based companies such as Google with its 'Search inside yourself' program, Facebook and Allied Mills with similar initiatives, and diverse Australian corporate, public sector, community, educational and sporting organisations, such as the Sydney Swans and Melbourne Football Club.

Along with these innovations has come an interest in mindful leadership (Carroll 2007; Sinclair 2007). While there is an increasing body of research documenting the links between mindfulness and leadership behaviours and attributes (see for example Brown and Ryan 2003; Shapiro, Carlson et al. 2006; Brown, Ryan et al. 2007; van den Hurk, Giommi et al. 2010; van den Hurk, Janssen et al. 2010; Hölzel, Lazar et al. 2011), the focus of this article is practical. I draw on experiences from introducing mindfulness practices and concepts to leaders and managers over the last seven or so years, asking: how can mindfulness enhance the quality of leadership? How might mindfulness enable leaders to have impact on valued outcomes but do so in ways that help others and themselves find happiness and meaning in their work?

Starting around 2006, my colleague Richard Searle and I began exploring how our shared interest in meditation and mindfulness could be incorporated into the work we do with leaders. This work now includes running

Correspondence concerning this article should be addressed to Amanda Sinclair, Melbourne Business School. email: a.sinclair@mbs.edu 
four-day Mindful Leadership programs for executives, which we began in 2007 and which includes experiential work encouraging mindfulness through yoga, meditation, insight dialogue and a range of other reflective practices. Mindfulness is also a key element in more mainstream executive development programs at Melbourne Business School which Richard co-directs and in the MBA and EMBA Leadership subjects that I teach. We have run academic forums on mindful leadership designed for researchers. The insights described in this article are drawn also from work with many professional, organisational and leadership groups, including in insurance, banking and engineering, with senior police and prison officers, academics and Indigenous leaders, school, health and hospital leaders. In my work coaching individual leaders, mindfulness is often a guiding practice. In work with these groups, the emphasis is on exercises, for example in listening, dialogue and meditation, occasionally breath work and yoga (for more details see Sinclair 2004; Sinclair 2007; Searle 2011; Searle 2013).

Although I started out thinking that this article should have a traditional academic framework - some definitions of mindfulness and mindful leadership, reviews of the literature, followed by the evidence and argument - I became increasingly unhappy with the result. In order to convey powerfully what I have learned about mindfulness and leadership, a different approach was needed. I decided to try and write mindfully as well as write about it. By this I mean to write simply and directly, from my experience and my heart, with less of the conventions that often accompany academic writing. I have also tried to make the article readable and helpful. My wish is that it may open up new avenues and insights for those who come across it.

Accordingly the article is organised around six insights. There's no magic to that number but when I honed in on what seem to be the important things, there were six!

\section{Putting people and their happiness first in leadership}

I came to mindfulness by the route of difficulty and pain - a not uncommon route, which is reflected in the first Buddhist noble truth: life is suffering. For me, 1996 was a tough year, with my brother's sudden death at 45 and the loss of my grandfather a few months later. I'd lost my Dad at 14 and Pop had become a beacon to all our family, with his humble self-sufficiency and generosity of spirit. My older brother had tried meditation and I took myself and my mother off to some free classes run by followers of Sri Chinmoy. I found the practice and teacher powerful, but life got busy in 1997 with the birth of my fourth child, Charlie, and I didn't return to exploring mindfulness until a subsequent (this time, career) crisis in 2003.

By that time I'd been a professor for some years, teaching and researching largely in leadership. On the outside, I appeared to be successful and influential. The crisis was that I felt I wasn't providing any leadership myself. I was participating in a punishing academic regime with its norms of sacrificing life to work. The 'leadership' I was part of seemed to be exacerbating suffering, not helping people find satisfaction and meaning in their lives. At a personal level l'd lost connection with what mattered to me as an academic and educator. Caught up with activities that didn't seem to make much difference, I felt 'stuck', distracted and unavailable to my family and friends.

Deciding to resign, the Dean at the time encouraged me to take leave without pay instead. During the following year, I sat in the garden and got RSI from overuse of the milk frother for lattes with friends. More usefully, I finished training to be a yoga teacher and read widely in yoga and Buddhist philosophy. I learned that the purpose of yoga is to improve one's capacity to understand and restrain the mind's 'modifications', that yoga body work is just the gateway. At the end of that wonderful year - the highlight of which was teaching Charlie and his 3 and 4-year old schoolmates yoga - I faced what seemed to be a stark choice: Yoga teacher or back to being a professor?

Initially and after completing further meditation teacher training with the Gawler Foundation, my efforts were around introducing yoga and meditation into the environments in which I was working. Increasingly, however, the opportunity seemed to be one of integrating mindfulness into the heart of leadership - both in how and what I teach.

For me, connecting mindfulness and leadership has meant:

- $\quad$ putting people's well-being and flourishing first and, at the very least, not adding to suffering in what I do and urge others to do

- $\quad$ taking off my armour and allowing myself to be vulnerable

- $\quad$ working with my whole self, my heart more than my head and trusting my senses 
- $\quad$ letting go of ego stuff, like needing the approval of others.

It has meant asking questions such as: How can leadership contribute to freeing people? How might leaders be helped to be more present to those they are seeking to lead? How can leadership reduce suffering, and support people to achieve great things, but also find peace and fulfilment?

Asking the questions above and seeking to make these changes in myself has evidently looked idealistic and sentimental to some. But it has become easier as I have stopped worrying about others labelling me 'naïve' or 'touchy feely' - a move facilitated by the recognition that those fears about how others see you are just the usual workings of ego and not to be given great importance.

\section{Mindfulness is not another form of thinking}

The first accounts of the principles of mindfulness date back to the Buddha's writings over 2,000 years ago. Still, today, the purest and simplest accounts of what it is like to be mindful come from the writings of those trained in Buddhism, such as His Holiness the Dalai Lama and Vietnamese Buddhist monk Thich Nhat Hanh (Hanh 1991). According to this view, mindfulness is bringing full conscious awareness to life or being awake to the present moment.

From the 1990s, mindfulness has been increasingly researched by psychologists, for example, Ellen Langer was a pioneer in showing how mindful practices helped delay and reverse mental and physical symptoms of ageing (Langer 1989; Langer 1992). Langer, however, adopted a very specific definition of mindfulness, as the capacity to categorise familiar stimuli in new ways and to elaborate new categories of thought.

But for our purposes it is important to make clear that mindfulness is not just another category of thinking, or even metacognition (on this distinction, see Purser and Milillo 2014). Rather, it denotes a state of attuned awareness of, and in, the present moment that is not cluttered by thought. Medical academic Craig Hassed has indeed suggested that a condition of excessive thinking is one of the key causes of stress in contemporary life (Hassed 2003; Hassed 2013). He and others have noted that we have an over-reliance on thinking, which often does us harm, and that mindfulness provides a very different mode of consciousness.

The features of mindful awareness are palpably different from thinking. In my experience, people can very readily identify when they are thinking, when they are reflecting (thinking about their thinking) and when their mind is closer to bare or mindful awareness. In thinking, the mind is often moving fast, and there is an orientation to problem-solving, evaluating and judging. It can also be repetitive, ruminative and even catastrophising, with thoughts like "what if this goes really badly?" When reflecting - which is arguably the basis for all deep learning - we consciously add a loop through the self, asking "why am I thinking about that, in the way I am right now?" In mindfulness we are not problem-solving or evaluating, not trying to change things or people, but rather in a state of open expansive awareness, able to notice - and appreciate - more of what's there. Each of these three states of mind (and undoubtedly others) is enormously valuable to us in doing our work and leading fulfilled lives. However, the evidence is that most of us have become over-reliant on thinking - we are our thoughts. In our experience working with leaders, they are more effective and inspiring when they bring mindfulness to the table, as well as superior thinking and the capacity to reflect.

\section{Don't get lost in neuroscience}

Often when I am asked to talk to groups of managers and leaders, the request is to provide the neuro-scientific or business 'case' for mindfulness. The data that provides 'hard' evidence that practising mindfulness does, indeed, improve capacities for focusing attention and reduce experienced levels of stress; that shows how the brain 're-wires' itself to support behaviours such as enhanced emotional intelligence; that shows benefits right down to genetic structures. There is an increasing amount of fascinating research available to support mindfulness in leadership (see, for example, Brown and Ryan 2003; Shapiro, Carlson et al. 2006; Brown, Ryan et al. 2007; van den Hurk, Giommi et al. 2010; van den Hurk, Janssen et al. 2010; Hölzel, Lazar et al. 2011).

However, waiting to be convinced by the neuro-scientific data and evidence about mindfulness is a thoughtproliferating process and a business-as-usual activity for the mind. It's good for leaders not to go down their usual technical or cognitive rabbit holes in seeking to explain, or justify, mindfulness. Most leaders do get that this is their usual approach. Further, research on organisational change suggests it that it is rarely rational empirical evidence that persuades people to do new and valuable things. As leadership researchers we see how, time and time again, individuals trying to mobilise change through presentation of the 'business case' fail. They are circumvented by political allegiances, vested interests, cynicism, paralysis, intellectualisation and 
a host of other familiar defences. What does sometimes open new insights and new possibilities for others is a leader's capacity to be present to current reality and courageous enough to name and advocate for what matters (Carroll 2007; Dalai Lama and Van den Muyzenberg 2008).

A related trap in much contemporary research on mindfulness is to equate the mind with the brain. In these accounts, mindfulness is sometimes treated as an artefact of superior brain functioning. This is a predictable pitfall for western trained researchers with their biases reproducing the dominance of the brain. When I work with smart people on mindfulness, their first port of call is often to try and make sense of it using their brain power, to think of it as adding another cognitive tool to the kit. As I have heard Sogyal Rinpoche advise, you don't have to worry about making sense of the experience.

Hence, the mind is different from the brain. For example, the mind can observe and discriminate among perceptions, thoughts and sensations occurring within the brain. 'Mindsight' is produced by neural pathways in the heart and the rest of body as well as the brain (Siegel 2009). While the brain is a physical organ which translates thought and emotion into electrical, biological and chemical activity and subsequently regulates other body functions, the mind is non-physical, constituted by thought and emotion (Hassed 2008).

In more traditional Buddhist and eastern accounts the mind's operations are not located just, or even at all, in the brain. For some, the mind is in the chest or heart area and there is some support that neural-like structures are widely distributed in the body - the sources perhaps of other kinds of intelligence, such as intuition. In yoga philosophy we are understood to have not one, but many, minds. Part of yoga practice is discerning which mind is active at particular moments and cultivating buddhi, or the discriminating mind. In sum, then, the best way to understand mindfulness and the mind is not to get too caught up in definitions or justifications but to help leaders observe and experience: to encourage people to go straight to awareness, where the stream of reactive thought is slowed and the mind rests on present sensations, such as the breath or bodily relaxation (Hassed 2013).

\section{You don't have to be in a cave or a retreat to be mindful}

A common view of mindfulness is that it is an intensely private process which people need to find time to go 'off-line' to do. Here, drawing a distinction between mindfulness and meditation may be helpful. While the two are deeply inter-related, meditation is a practice of sitting (or walking) in a state of conscious awareness, while mindfulness is bringing a state of awareness to whatever we may be doing. Writers such as Thich Nhat Hanh and contemporary teachers such as Kabat Zinn emphasise that mindfulness is of limited value if we are not seeking to live it in our relationships with others, our work and everyday lives. And this is why mindfulness has such potential for leadership: because it can be practised in the thick of whatever we are doing or wherever we happen to be. We can wash dishes with mindfulness, or have a conversation with mindfulness. The evidence is that others involved in those moments will notice a difference. They will feel more heard and more held to embark on whatever challenge that is before them.

Leaders in all spheres are facing pressures to do more with fewer resources. They have workloads they never feel on top of, and are often charged with letting go of good people and doing very difficult things. Many feel they are on the edge, close to breaking. They can't see another way forward but more of the same, though they fantasise about escape. Sometimes their personal relationships are under intense strain. Relations with family and friends, as well as health, are the casualties of staying later at the office at night or having to go on yet one more international or interstate trip. Leaders lose sight of the pleasure and satisfaction they may have gained from work, and instead feel ground down. When we together explore some of the pressures they are under, and some of these effects, their first response can be, "But that's just leadership, isn't it? That's the job."

It is perhaps tempting in this context to treat mindfulness as a stress management tool which will enable leaders to weather the storms of work and life, to sail more skilfully into the wind ${ }^{1}$. Although it is true that practising mindfulness often helps people cope with stress, to just treat it as a tool would be to miss many other profound opportunities that arise from being mindful. Rather than lashing ourselves to the mast of life, driving ourselves harder, mindfulness can open the door to being in the world and in our lives differently, without being hounded by the relentless drive to change ourselves or others.

\footnotetext{
${ }^{1}$ This metaphor comes from Paul Bedson, a meditation teacher at the Gawler Foundation when I did some training there.
} 
When we introduce leaders to these possibilities, they sometimes hear us as advocating retreat to a softer, less impactful working life. "How would I get anything done - which is what I am paid for!" some protest. Yet it is our experience that mindfulness often allows for more impact, not less. Dropping down from the incessant drive, or what the Buddhists call 'striving', allows space for the critically important things to be seen and acted upon, for leadership to be lived and even relished, rather than just 'got through'.

Among the reasons why many of leaders seem to find mindfulness useful is that they can, very directly in a workshop setting or even better, over a couple of days, get an experience of being quieter and stiller, despite the often chaotic and intense demands on them. Even briefly, this experience of observing their thoughts about the situation rather than being captured in them, opens up an option that wasn't there before: that they can choose their reaction. Seemingly simple but also profound, in the short term there may be no change to what's happening to us or around us. Mindfulness simply allows us to be with those happenings in a less reactive way.

In some cases, as in a large multi-campus hospital with which I was working, there was already a lot known about and being done with mindfulness, especially in areas of palliative care. In another couple of examples of working with P-12 school leadership teams, mindfulness was something that students and parents had been introduced to as part of staying healthy and coping with pressure. In one school, many teachers had already been trained to work with mindfulness with the class groups, drawing on a range of programs and exercises tailored to the year level of their students. My role was to show how mindfulness was not just a very useful tool to help with stress but could make a central contribution to school leadership and in growing empowering school cultures (which most schools are also very keen to embed). In their educational settings, teachers are often more used to talking than listening, and they are expected to give advice and problem-solve. Teachers already know that the most sustainable solutions for students are usually the ones they come up with for themselves when supported to do so. Mindful leadership puts a central value on being present with others. For many of these teachers, mindfulness helps them find a different and deeper place from which to listen to students: one that doesn't necessarily take more time but creates a space in which students feel held to find a new path themselves.

Mindfulness in leadership has been highly relevant for other groups - from senior international police officers, through to women in leadership programs, groups of young community leaders, corporate executives, librarians, academics, unionists - with ostensibly different and very serious leadership challenges. Senior police officers experience excessive workloads, issues such as people trafficking and organised crime where the stakes and burnout are high. There are lots of things which pull them away from their core work of mobilising their staff to keep on tackling very difficult challenges where solutions are scarce. They found that mindfulness helped them reconnect with and re-validate some of the strengths and skills that they had often developed early in career: to bring a highly focused yet open attention to the phenomena which they are seeking to address. What we almost invariably find is that ideas of mindfulness and the glimpses of getting stiller or listening more deeply, resonate powerfully with these groups.

Associated with mindfulness and reduced reactivity is the possibility of letting go of some things. Many leaders carry around in their heads ideas like "I can't let them down" or "it's my job to do those difficult things - that's what I'm paid for". Frequently these are punitive ideas or beliefs which are actually not functional or useful any more. In letting go of them, leaders often find they are of more use to the people around them because their interactions are not overshadowed by these 'shoulds' and they can find a different place from which to tackle challenges.

A beautiful quality that sometimes unfolds with groups experimenting with mindfulness is appreciation. Whether it's in newly-formed groups of strangers or in intact leadership teams, the processes of slowing down and listening more fully and deeply means that people hear things from others that they would ordinarily miss. Mindfulness helps people notice and step back from default responses such as biases and stereotypes. I've seen management teams 'see' one of their members as if meeting a new person with a whole range of previously overlooked contributions. I've also seen people share profound things about themselves with others who are pretty well strangers, a process which often ushers in for both parties a deep appreciation of the common humanity, and common experiences, binding us all.

Further, leaders often tell us that an impact of mindfulness is a reconnection with family. Kids notice that they've got their dad's attention in a way they've got used to not having. Children remark that their parents are smiling more, that they're not looking at their phone all the time, and that they listen to them. Often participants will sign up to do some classes on meditation, yoga or pilates with their partner or other family 
member. For me this is often one of the most satisfying pieces of feedback about the impact of mindfulness. There is sometimes a very quiet, almost stunned, air about groups working on mindfulness. It is as if they are remembering or reconnecting with a way of being that they'd lost sight of, but have again glimpsed, and feel they can retrieve.

Where workplaces contain mindful practices, such as pausing to allow deeper and more reflective dialogue among group members, some important changes seem to occur (Searle 2011; Searle 2013). People feel more respected and listened to. Employees are supported to pay attention to their health and well-being, to set boundaries and negotiate ways of looking after themselves, whether it's working from home sometimes, turning blackberries off on weekends, or leaving work early or starting late on one or two days a week. It is even more powerful when employees see leaders doing this, because it gives them permission for themselves. A result is that people enjoy work more, with lower rates of turnover and stress-related absenteeism.

Further, there is often a sense of common engagement around purpose. This is not a case of the 'vision statement' handed down as an edict from on high. Purpose is collectively re-visited and refined: what matters to us here? How are we trying to make a difference? In the case of a private company we know about, this collective and mindful engagement with purpose results not only in fulfilled employees and an active philanthropic program but improvements in business metrics as well, such as the quality of client relationships and amounts invested by those clients.

While these observations are based on our direct experience, there is growing leadership research which also documents the impact on work and workplaces of leaders who bring to their leadership work some of the mindful qualities we've explored here (Boyatzis and McKee 2005; Carroll 2007). These include the impacts of leaders who are able to gain perspective on and intervene purposefully in the action (see, for example, (Heifetz 1994; Heifetz and Linsky 2002); leaders who by being wholly present make different possibilities available to those around them (Senge, Scharmer et al. 2004; Scharmer 2009); leaders who can focus their attention on what matters, initiating difficult but transformative dialogue (Isaacs 1999); and leaders who prevent and manage crises better through close 'noticing' rather than enacting default routines.

\section{What we seek to do with mindfulness matters}

Organisational mindfulness initiatives are undertaken for a whole range of reasons: to help employees deal with work pressures and stress; to improve workplace climate and encourage people to listen better to each other; to help with priority-setting; to foster innovation and creativity. While mindfulness can contribute to these valued outcomes, in our experience, purpose and values are central to mindfulness. Almost inevitably, practising mindfulness calls leaders to ask how they are spending their energy and their lives.

Mindfulness was originally taught by the Buddha to help devotees come to grips with suffering and the causes of suffering in the world. As a practice it has always been oriented to helping others be happier and relieved of pain and suffering. According to these teachings, all of us have a Buddha within and the capacity for enlightenment. Beginner's mind is valued - not expert scientific mind. Central to mindfulness is the devolving, democratic recognition that all beings deserve freedom from suffering. It is not an approach that should be used to reinforce hierarchies, organisational or expert power.

This is the ethical context of mindfulness that is so important to its meaning (Purser and Milillo 2014). To introduce mindfulness into an organisation in order to make more money or improve competitive position, or even to improve innovation and productivity, may leave out a central, perhaps the most central, mindful teaching. This is the concern sometimes expressed about organisations such as the US military teaching mindfulness to combat soldiers whose job it is to crush the enemy. We should be concerned when mindfulness is put to the wheels of global capitalism, enabling people to feel less stressed about doing immoral things, or in less obvious ways feeding exploitation, punishing work cultures or unsustainable materialism.

Buddhist writer, Chogyam Trungpa, warns about the risk of spiritual materialism (Trungpa 1973). As he explains, people are good at using spiritual insight to 'get somewhere' or display their own wisdom. The ego can turn anything to its own use. If we are interested in mindful leadership, we are seeking to notice when mindful practices get used to prop up ego, to make us feel more self-satisfied perhaps at the expense of others. Yet Thich Nhat Hahn shows characteristic equanimity about this risk, arguing that if people engage genuinely in mindfulness then gradually a re-orientation of purpose follows (Confino 2014). Further, the evidence is that organisational employees are good at detecting when an initiative is nakedly instrumental: they have sharpened 'bullshit detectors' and won't willingly involve themselves in something that feels like it is being run for manipulative reasons. 
While everyone who comes to meditation and mindfulness does so with their own history and experiences, a central part of the process which often unfolds is an exploration of values and ethics. Mindfulness can thus offer very practical ways of helping people stay grounded in reality and connected to what matters to them. It can help them notice when they get caught in excessive driving and striving which is not good for them or the people around them. In our experience this practically grounded ethics is welcomed by leaders. Many make changes in their leadership, their careers or organisations to better serve a purpose or set of values that may have felt jeopardised.

\section{Beware of ego, and practise - not preach - mindfulness}

In leadership, there are lots of fads and lots of egos. Consultants and academics like myself often compete to offer the last word on leadership and provide advice that will help leaders do their jobs better. As described above, mindfulness is also increasingly being taken up by organisations and business. While this coming together of leadership with mindfulness is potentially of great benefit, there are pitfalls for those of us who work with leaders in this space.

One is the risk of getting so attached to mindfulness or a particular template for doing it, so intent on its benefits, that one preaches rather than practises. We start selling it and telling it, rather than respecting where people are at. Problems have arisen for me when I have become too attached to my role in advocating mindfulness or to the programs we have developed. If I get over-zealous in citing the benefits, I miss the point. Jon Kabat Zinn is one of a number of meditation teachers and researchers who advises that if one starts to advertise meditation, or tell someone else that meditation would be good for them - do more practice!(KabatZinn 1994; see also Michie 2014)

Another pitfall is that in leadership we also often lionise the heroic individual. There is a long history in leadership research and practice of looking to gurus or saviours to give us the answer (Heifetz 1994). It is useful to remember that we can't do leadership or mindfulness within this individualistic paradigm. In mindfulness we are just a small part of a long and rich lineage of teaching. Similarly, effective leadership is never a solo activity. For me, my yoga and meditation teachers have provided inspiration for me to be courageous, while acknowledging and appreciating the support of many others. My work and practice have benefited immeasurably from many teachers, students, family and friends such as Richard, who've helped me to be respectful and compassionate, rather than pursuing my own agenda or being trapped in my ego needs.

\section{CONCLUSION}

Commencing yoga and beginning my own mindfulness journey around 20 years ago has had profound consequences for me. Initially at a personal level and later in my work with colleagues and leaders, mindful teachings and practices have helped me deal with difficult circumstances and, more significantly, helped me relish and find joy in work and life. While it has not been a straightforward or simple trajectory, exploring mindfulness has enabled me to do my leadership work differently - with more love and less judgement of myself and others.

In this article I have drawn on my own experience to show how the practice of mindfulness can enhance leadership. It does so by giving individuals seeking to exercise leadership some new ways of being in the work and by improving their positive impacts on those they work alongside. Many of the leaders we encounter in our work are truly inspirational but it's also true that most are also suffering. They are struggling to do their work effectively and purposefully, with grace and intent, but with less mental and physical cost to themselves and the people working alongside them. You could say that there is an epidemic of suffering in many workplaces. That situation can be changed, and it may be that it can be changed through a commitment to individuals persisting with some quite simple acts: being present and paying attention to what's really happening, being connected to others and appreciative of their efforts, being reflective about our own 'stuff', and letting go of some of the ebbs and flows of ego, and being courageous about reality and what matters most in life. 


\section{ACKNOWLEDGMENT AND AUTHOR PROFILE}

Acknowledgment: Although I have written this article, the ideas expressed here have been arrive at jointly and collaboratively, and I wish to particularly acknowledge my great friend and colleague Richard Searle, who has taught me much about mindfulness and leadership.

Amanda Sinclair is an author, teacher and consultant in areas of leadership, change, gender and diversity. A Professorial Fellow at Melbourne Business School, The University of Melbourne, her books include: Leadership for the Disillusioned (2007) and Doing Leadership Differently (1998, 2005). Much of Amanda's recent work has involved helping organisations and leaders introduce mindfulness to their leadership work and she is writing a new book on leading mindfully. Also a yoga teacher, she is interested in the physicality of leadership and supporting people to find sustainable, pleasurable ways of being in leadership.

\section{REFERENCES}

Boyatzis, R. and A. McKee (2005). Resonant Leadership: Renewing yourself and connecting with others through mindfulness, hope and compassion_Boston, Massachusetts, Harvard Business School Pres.

Brown, K. W. and R. M. Ryan (2003). "The benefits of being present: mindfulness and its role in psychological well-being." Journal of personality and social psychology 84(4): 822.

Brown, K. W., R. M. Ryan, et al. (2007). "Mindfulness: Theoretical foundations and evidence for its salutary effects." Psychological Inquiry 18(4): 211-237.

Carroll, M. (2007). The Mindful Leader: Ten principles for bringing out the best in ourselves and others. Boston, Trumpeter.

Confino, J. (2014). Thich Nhat Hanh: Is mindfulness being corrupted by business and finance? the guardian.com.

Dalai Lama, H. H. t. D. and L. Van den Muyzenberg (2008). The Leader's Way. London, Nicholas Brearley. Hanh, T. N. (1991). The Miracle of Mindfulness: A Manual on Meditation. London, Rider.

Hassed, C. (2003). Know Thyself: The stress release programme Melbourne, Australia, Michelle Andersen.

Hassed, C. (2008) The essence of health: The seven pillars of well-being. North Sydney, NSW: Ebury Press.

Hassed, C. (2013). Driven to distraction: Why be mindful in this unmindful world? Life Surfing Life Dancing. G. Blashki and H. Sykes. Sydney, Australia, Future Leaders: 43-66.

Heifetz, R. A. (1994). Leadership without easy answers, Belknap Press.

Heifetz, R. A. and M. Linsky (2002). "A survival guide for leaders." Harvard Business Review 80(6): 65-74.

Hölzel, B. K., S. W. Lazar, et al. (2011). "How does mindfulness meditation work? Proposing mechanisms of action from a conceptual and neural perspective." Perspectives on Psychological Science 6(6): 537-559.

Isaacs, W. (1999). Dialogue-and the art of thinking together. New York, Random House Inc.

Kabat-Zinn, J. (1994). Wherever you go, there you are: Mindfulness meditation in everyday life. New York, Hyperion.

Langer, E. J. (1989). "Minding matters: The consequences of mindlessness-mindfulness." Advances in Experimental Social Psychology 22: 137-173.

Langer, E. J. (1992). "Matters of mind: Mindfulness/mindlessness in perspective." Consciousness and Cognition 1(3): 289-305.

Michie, D. (2014) Why mindfulness is better than chocolate. Crow's Nest, Sydney: Allen \& Unwin.

Purser, R. E. and J. Milillo (2014). "Mindfulness Revisited A Buddhist-Based Conceptualization." Journal of Management Inquiry: 1056492614532315.

Scharmer, C. O. (2009). Theory U: Learning from the future as it emerges, Berrett-Koehler Publishers. 
Searle, R. (2011). "Could it be as simple as listening?" www.searleburke.com.

Searle, R. (2013). "Seven Elements of Insight Dialogue." www.searleburke.com.

Senge, P. M., C. O. Scharmer, et al. (2004). Presence: Human purpose and the field of the future, SoL Cambridge, MA.

Shapiro, S. L., L. E. Carlson, et al. (2006). "Mechanisms of mindfulness." Journal of Clinical Psychology 62(3): 373-386.

Siegel, D. (2009) Mindsight: Change your brain and your life. Melbourne: Scribe.

Sinclair, A. (2004). "Renewal." Mt Eliza Business Review 7(1): 38-44.

Sinclair, A. (2007). Leadership for the Disillusioned: Moving beyond myths and heroes to leading that liberates. Crow's Nest, Sydney, Allen \& Unwin.

Trungpa, C. (1973). Cutting Through Spiritual Materialism. Boston, Massachusetts, Shambhala Press.

van den Hurk, P. A., F. Giommi, et al. (2010). "Greater efficiency in attentional processing related to mindfulness meditation." The Quarterly Journal of Experimental Psychology 63(6): 1168-1180.

van den Hurk, P. A., B. H. Janssen, et al. (2010). "Mindfulness meditation associated with alterations in bottomup processing: psychophysiological evidence for reduced reactivity." International Journal of Psychophysiology 78(2): 151-157. 